\title{
An Event Tree Model for Estimation of Fire Outbreak Risks in Case of Large-Scale Earthquake
}

\author{
HIDEKI KAJI \\ University of Tsukuba, Japan \\ TETSUYA KOMURA \\ Nippon Univac Kaisha, Ltd., Japan
}

\section{ABSTRACT}

This paper aims to develop a new method for estimating fire outbreak risks in the case of a large-scale earthquake using computer simulation technique, in which causal relationships concerning fire outbreak are modeled as an event tree structure. As a case study, kitchens for commercial use were taken, and about 5,000 kitchens of different types of business were surveyed particularly in terms of the fire appliances used therein. An event tree structure was designed on the basis of practical causal. relations of 55 fires which broke out in past earthquakes. Monte Carlo simulation technique was applied for estimating fire outbreak risks by business type. Although many questions remain unanswered, the usefullness and high applicability of this method are clearly shown.

\section{INTRODUCTION}

In Japan a number of earthquakes have taught us that damage caused by seismic city fire is more severe than that caused by the actual collapse of houses and other urban facilities when a largescale earthquake hits the Tokyo Metropolitan Area. Prevention of seismic city fire is therefore considered the most important mitigation policy in Tokyo.

According to the Tokyo Disaster Prevention Council, it is estimated that inres would break out simultaneously at about 300 places: 208 fires could be extinguished by Metropolitan Fire Services, but 92 fires would spread uncontrollably over the city.

Obviously, this kind of estimation is essential for formulating an appropriate earthquake prevention plan. Thus, many efforts to estimate the number of seismic fires have been made. However, a truly reliable method has not yet been developed. The most popular and well-known method is the Kawazumi's formula, on which the above mentioned estimate is based.

However, Kawazumi's formula is criticized because it depends too much on data which is basically drawned from the Kanto earth- 
quake of 1923. Fire appliances and life styles have changed radically since then, therefore Kawazumi's statistical model can not be directly applied today.

This paper aims to develop a new method for estimating fire outbreak risks in case of a large-scale earthquake, by computer simulation technique in which causal relationships concerning fire outbreak are modeled as an event tree structure.

\section{ASSUMPTIONS AND DATA COLLECTION}

In this study, it is assumed that the magnitude of the earthquake is 7.9 , which is the same as that of the Kanto earthquake. This means that the acceleration at the ground level is about 250 to $400 \mathrm{gal}$, and the response acceleration of a building is about 980 gal.

The basic structure of the model is designed by formulating the interactive behavior between some fire appliances and its surrounding combustible materials when the buildings are quaked with such acceleration.

In general, fire appliances vary in kind, e.g., for cooking, for heating, for manufacturing, and they are used in different places and situations. It would be too much to develop a general model that covers each different case.

In this paper, a commercial kitchen and the fire appliances used therein are taken as a case study. This is the most dangerous case from the viewpoint of fire outbreak risks and from casualty resulting from the quake, since the commercial district is where many non-resident customers gather during the day time.

About 5,000 kitchens from different types of business were surveyed, particularly in terms of the fire appliances used there. The business were classified into eight types, they are as follows:

1. Nightclub and bar

2. Japanese restaurant

3. General restaurant

4. Department store

5. Retail store

6. Hotel.

7. Hospital and clinic

8. Kindergarten

With regard to the fire appliances, it was observed that more than 20 different kinds of fire appliances were used in the kitchens. In this study, however, three major fire appliances normally used in every kitchen are counted as a fire source. They are; gas heater, gas table and gas range. The average number of fire appliances used in a kitchen was about 1.5 units.

Based on this obervation, simulation cases by business type, which will be discussed later, were set up. This paper focuses mainly on how to design and operate the event tree model (Figure 1). 


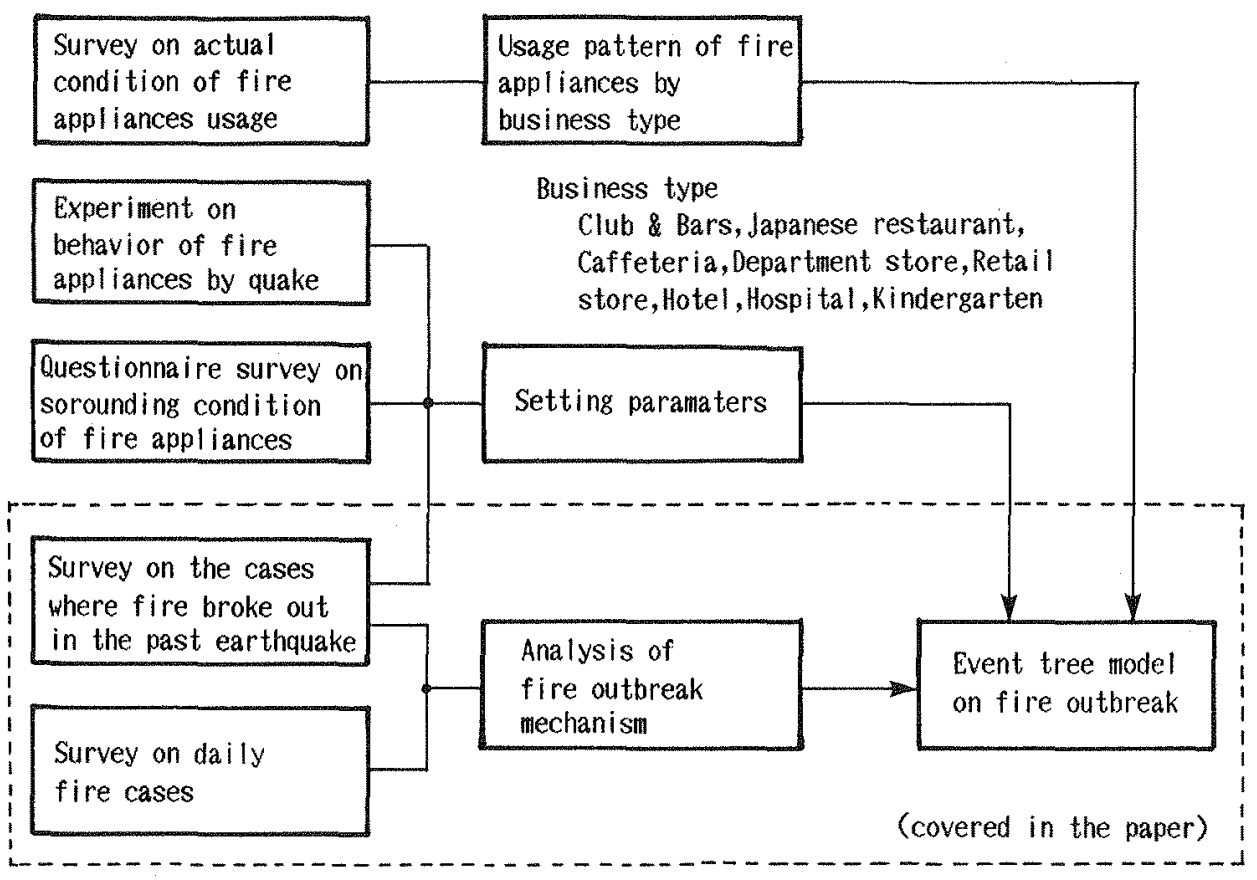

FIGURE 1. Diagram of the study

\section{DESIGN OF EVENT TREE STRUCTURE OF FIRE OUTBREAK PROCESS}

As the first step for designing the event tree structure of fire outbreak process, three major earthquakes that occurred during the past 20 years were carefully examined. They are: Niigata earthquake (1964), Tokachioki earthquake (1966), and Miyagiken-oki. earthquake (1978). According to the reports, 55 fires broke out in these three earthquakes. Figure 2 and 3 show main causal relationship of events which led to the fire. Based on this analysis, referring causal factor of the daily fire case, a general cause and effect structure of fire outbreak was designed (Figure 4). As an exogenous condition for applying this model, typical usage patterns of fire appliances by business type were also set up.

Causal relationships as seen in figure 4 can normally be described as a stochastic process using probability of how frequently each event happens. This causal relation model, however, consists of multiple feedback loops which make it difficult to describe by simple stochastic equations of the conditional probability. Thus, the Monte Carlo Simulation Method that random numbers are generated according to the occurrence ratio exogenously assigned is applied.

The structure of the model is basically divided into three parts. They are; description of human behavior, dynamic movement of fire 


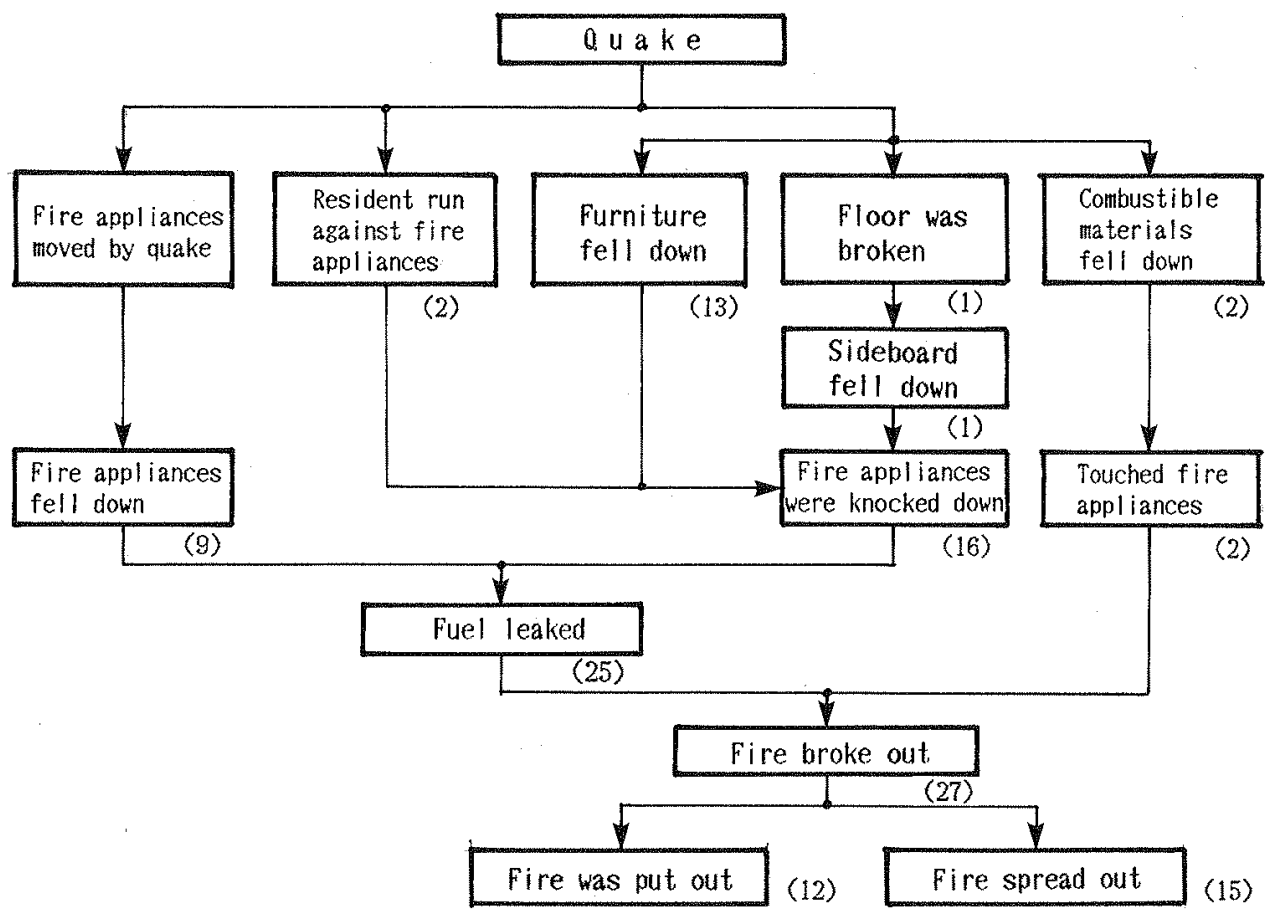

FIGURE 2. Fire outbreak process by liquid fuel of oil stove and oil heater

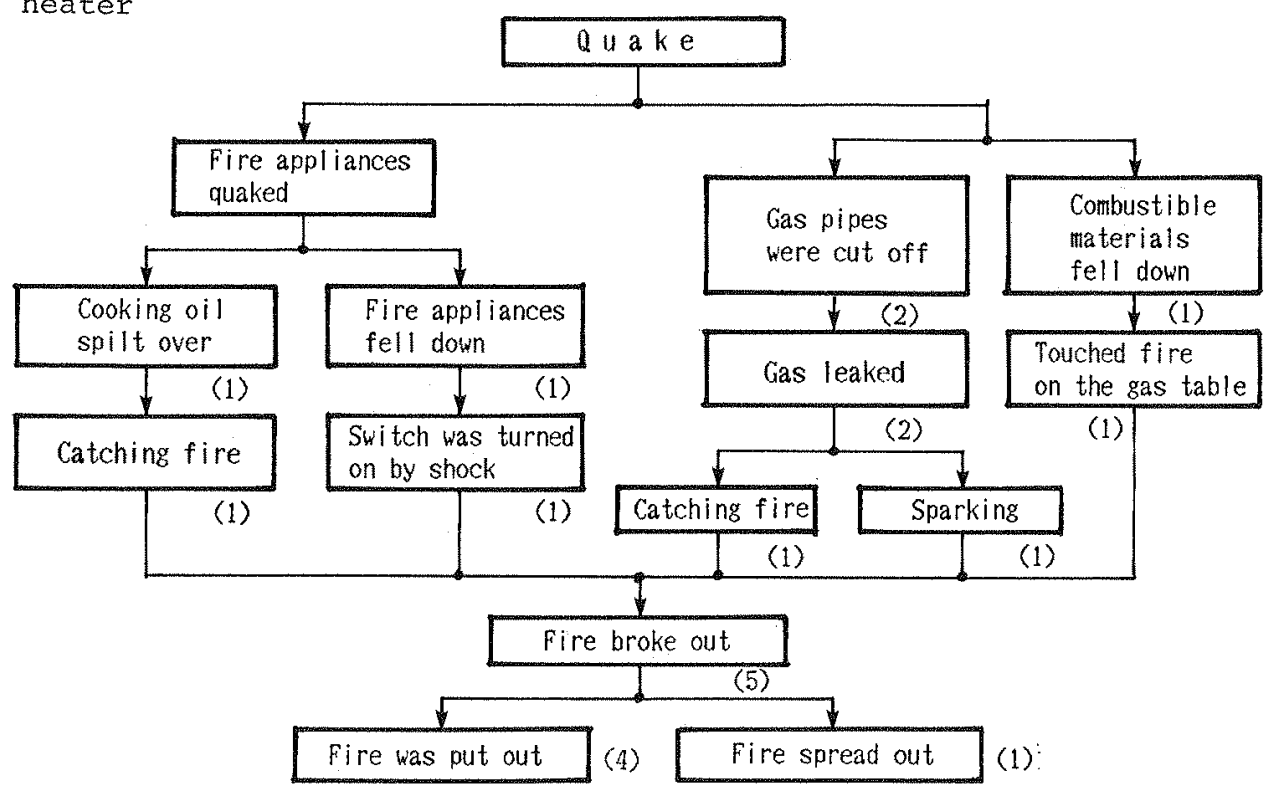

FIGURE 3. Fire outbreak process by gas fuel of cooking gas table 


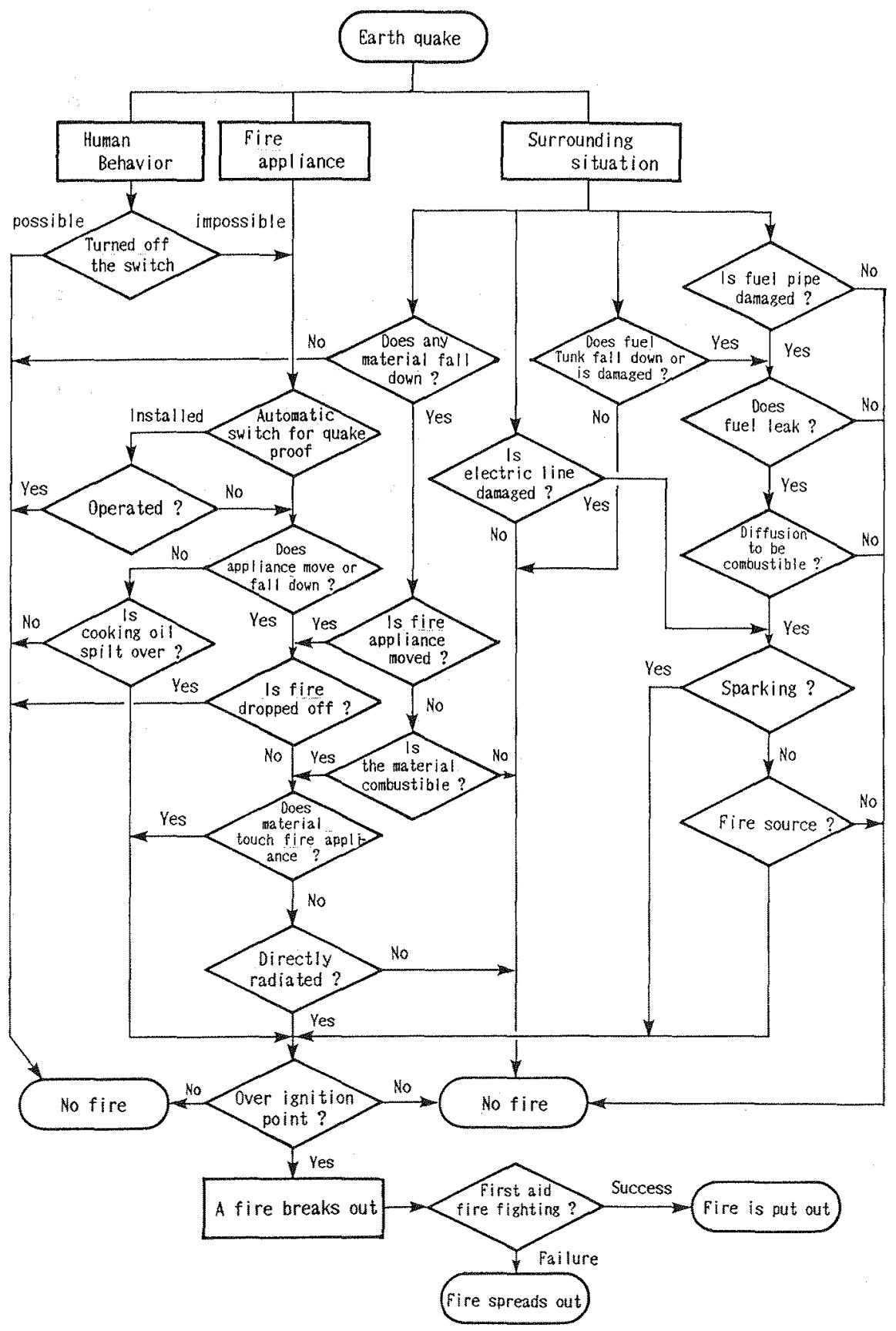

FIGURE 4. Event tree structure 
appliance caused by quake, and change of circumstance. As seen in figure 4, an event happening in one part causes another event in the other part. The model describes this interaction between three parts on the time series basis. It should also be noted that the chance that a particular event would occur or not, may depend totally on whether suitable conditions for the event is formed at that particular time. A bit of time lag plays an important role for an event to occur.

\section{SPECIFICATION OF PARAMETER}

In order to operate this computer simulation model, several parameters which control the occurrence time and frequency have to be established exogenously. Not so many parameters, however, can be specified with a reasonable amount of accuracy based on the experimental results or past earthquakes, because the kanto earthquake is too old to be of accurate reference and recent earthquakes are not as big as the one being assumed in the study. Thus, some parameters which we specified cannot always be justified practically. The basic strategy for parameter specification in this study is as follows:

a. To utilize the knowledge from experiments, if any. (Such as the behavior of appliances by quake, leak of fuel or spilling over of the cooking oil by quake, and the flashing point of oil by overheating.)

b. To apply the theoretical model in the engineering field. (Such as the computation of the response acceleration of a building.)

c. To refer the experience of the past earthquake. (Such as the breakdown ratio of the gas piping and the possibility of fire fighting at an early stage.)

d. To utilize the experience of daily fire cases. (Such as time until ignition or flash point.)

e. To keep the balance between parameters through intuitive insight based on inspection by experts on fire-proofing.

Some parameters which are difficult to specify are set tentatively first and modified later through sensitivity analysis, so that outcomes are reasonably stable in a common sense for experts in fire fighting (Figure 5).

\section{ESTIMATION OF FIRE OUTBREAK RISKS}

In order to estimate fire outbreak risks by applying the model described earlier, a pattern of fire appliance usage which is characterized by type and number of fire appliances, number of operators and operation place, has to be specified.

These characteristics vary with the type of business mentioned earlier and therefore, estimation of fire outbreak risks by a usage pattern of fire appliances can be directly translated into that by the type of business. In figure 6 , as an example, the results from a kitchen in a typical restaurant with the following usage pattern of fire appliances is shown (Table 1). 


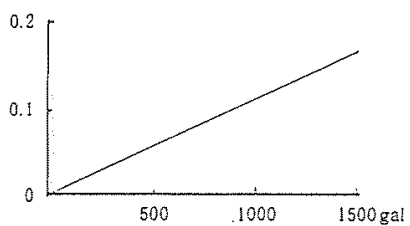

(a) Breakage of fuel tank

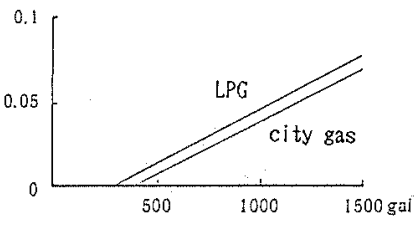

(b) Breakage of gas pipe

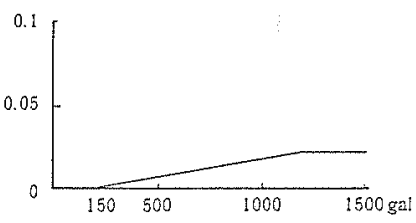

(c) Appliances surrounded to fall

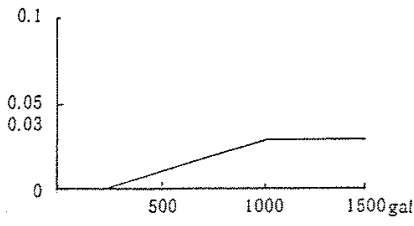

(d) Spark generation

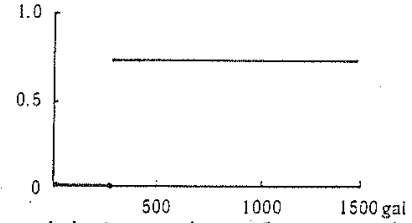

(e) Operation of automatical switch for quake proof

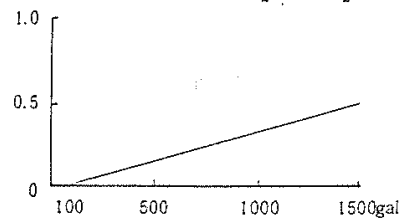

(f) Movement of fire appliances

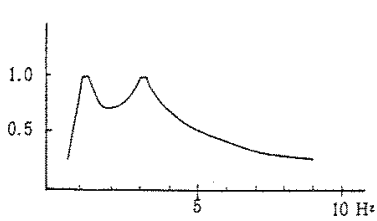

(g) 011 to be spilt over

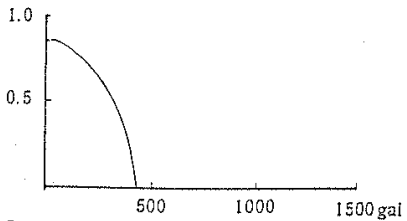

(h) Switch-off by residents

FIGURE 5. Occurrence probability of each event

TABLE 1. Usage Pattern of Fixe Appliances

\begin{tabular}{lcc}
\hline Response acceleration of the building & 482 gal \\
Fire appliances & gas ring & 1 piece \\
& gas range & 1 piece \\
& frying machine & 1 piece \\
Operators (cooks) & & 2 persons \\
\hline
\end{tabular}

The digits seen in figure 6 show the average frequency of occurrence of each event obtained through ten times of computation, each of which generates random number 5,000 times.

First it was judged whether the switch of the fire appliances could be turned off by the cooks working in the kitchen. In this result, the switches were turned off only 709 times out of 15,000 attempts on three appliances. This means that on average only one fire appliance out of three can be switched off by people. The next step is to compute how the appliances on fire would react. Some materials which were kept nearby fell down 214 times out of 5,000 times and they touched and moved fire appliances 48 times. As a total, fire appliances moved 528 times.

Fire of the fire appliances was put out naturally 1,337 times by movement, materials falling down and other reasons. When materials kept nearby fell down, they could touch fire directly, and fire would break out if these were combustible. This event occurred 66 times in this computation. Frying machine was kept on fire 3,789 times and as a result, oil contained was overheated, and 36 fires broke out by this process. In some cases oil was spilt over by 


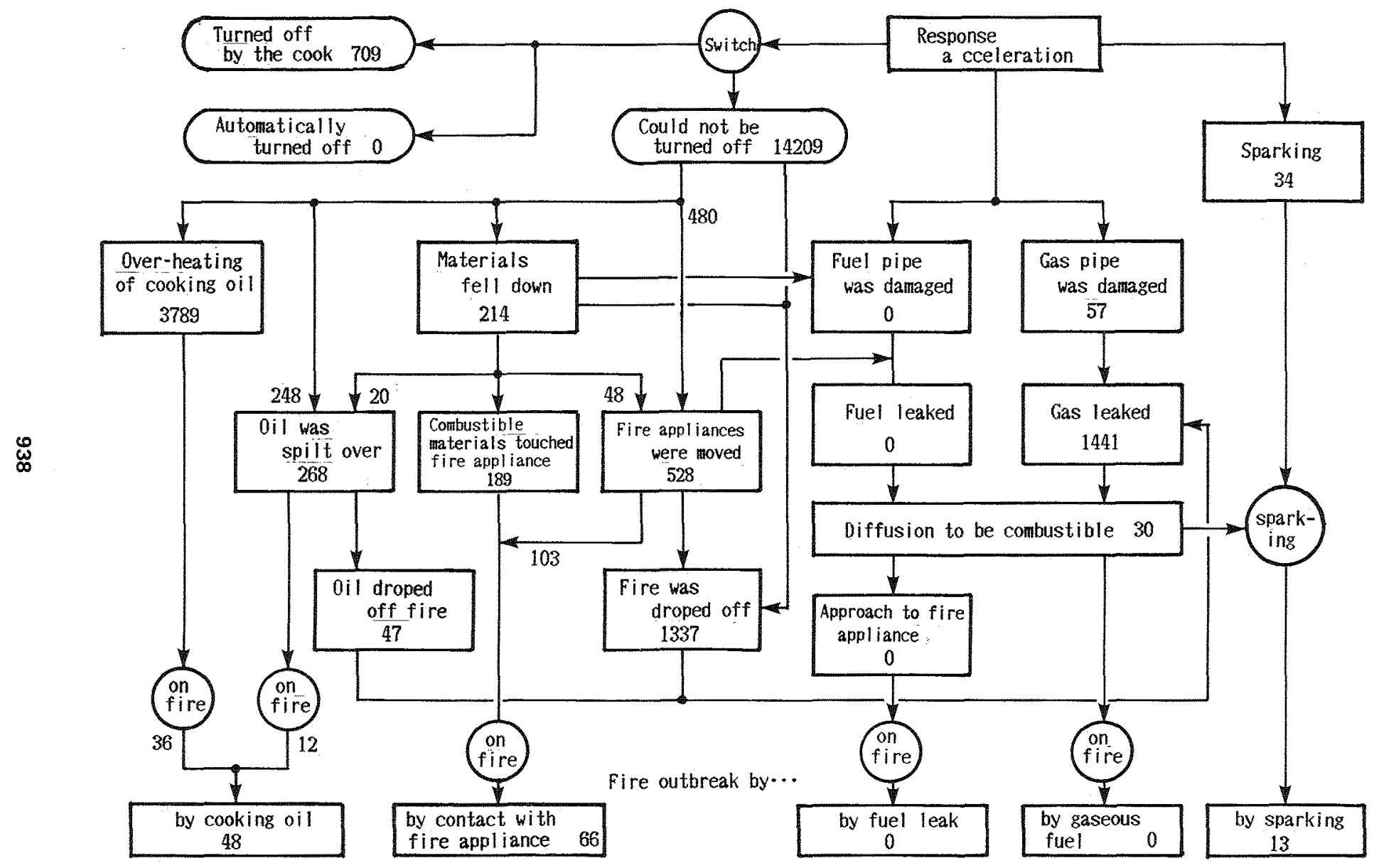

FIGURE 6. An example of outcome of fire outbreak estimation 
quake, 12 fires broke out through burning oil. As a result, a total of 48 fires were caused by oil. The total number of fire outbreak was 127 in this case. Therefore, probability of fire outbreak can be computed as 0.0254 .

In order to compute the average probability of fire outbreak by business type based on this simulation result, the following formula was applied.

$\mathrm{P}=(\mathrm{PO} * \mathrm{UO}+\mathrm{Pm}) * \mathrm{Uf} * \mathrm{Fe} * \mathrm{Cm}$

Where P: Probability of fire outbreak by business type

Po: Simulation result of fire outbreak by oil

Uo: Usage ratio of frying pan

Pm: Simulation result of fire outbreak by other fire source

Uf: Fire appliance usage ratio

Fe: Failure of fire extinguishing operation multiplier

$\mathrm{Cm}$ : Combustible materials multiplier

Table 2 shows the average probability of fire outbreak by business type computed by the above formula. The results are different on the ground condition. In case of the soft ground (clay), the probability is about 50 per cent over that of the hard ground (loamy soil). The kitchen of a restaurant is the most dangerous. This means that the fire outbreak risks is high in the commercial district where these facilities are concentrated.

TABLE 2. Fire Outbreak Risks by Business Type

\begin{tabular}{lcc}
\hline & \multicolumn{2}{c}{ Fire outbreak Risks (o) } \\
\cline { 2 - 3 } Type of Business & $\begin{array}{c}\text { Hard ground } \\
\text { (loamy soil) }\end{array}$ & $\begin{array}{c}\text { Soft ground } \\
\text { (clay) }\end{array}$ \\
\hline Nightclub and bar & 0.29 & 0.41 \\
Japanese restaurant & 0.30 & 0.40 \\
General restaurant & 0.32 & 0.46 \\
Department store & 0.17 & 0.20 \\
Retail store & 0.12 & 0.17 \\
Hotel & 0.19 & 0.25 \\
Hostel and clinic & 0.06 & 0.08 \\
Kindergarten & 0.10 & 0.13 \\
\hline
\end{tabular}

Major causal routes to fire outbreak cases are as follows:

a. Fire appliances on fire $\longrightarrow$ overheating of cooking oil $\longrightarrow$ Fire outbreak

b. Kitchen appliances moved or fell down $\rightarrow$ Contacted with combustible materials $\longrightarrow$ Fire outbreak

c. Cooking oil spilt $\longrightarrow$ Contacted with fire source $\longrightarrow$ Fire outbreak

d. Combustible appliances moved $\longrightarrow$ Damaged gas pipe $\longrightarrow$ Gas leaked $\longrightarrow$ Sparking $\longrightarrow$ Fire outbreak

e. Boiling soup spilt over $\longrightarrow$ Flame of gas stove put out $\longrightarrow$ Gas leaked $\longrightarrow$ Sparking $\longrightarrow$ Fire outbreak

Although cases of $d$ and e have not occurred yet in the past earthquakes, possibility of occurrence in the future is very high in areas where liquid propane gas is used. 


\section{VALIDITY OF THE MODEL}

Validity of the model should be tested by reference or comparison with practical data in a past earthquake or experimental results. In this model, however, there are neither large earthquakes, except the Kanto earthquake, nor any real scale experiment to which the model could be referred. Therefore, instead of applying the normal validity test, intuitive insight and the expertise of skilled inspectors of fire-proofing were used to check the results of the estimation from the following viewpoints:

I. Whether they felt that the relative occurrence ratio and order of each phenomena were reasonable.

2. Whether they felt that the estimate of fire outbreak risks matched their intuition.

3. Whether they felt that the occurrence ratio of fire by business type was reasonable.

The results of the estimation was thought to be acceptable by the inspectors. The estimated sum of the number of fire outbreaks in the Tokyo Metropolitan area, obtained by muliplying the fire occurrence ratio by the total number of business, comes to 2,000 . This figure appears to be too large for the number of fires occurring in the kitchens of the special types of business. Apart from these, other sources such as housing, chemical factories etc. must be taken into consideration. In which case the number of fires in Tokyo would double. This seemed to be unimaginable.

Thus it is suggested that this model be examined further from the following viewpoints.

1. The season or time when the earthquake would take place should be considered and introduced to the model so that the usage ratio of fire appliances can be reduced.

2. Fire source would not be left so long because people may put out the fire after the first strong quake finishes. In which case the fire outbreak caused by overheating of cooking oil or other similar sources may be avoided.

3. Parameters should be examined more carefully.

\section{REFERENCES}

1. Tokyo Fire Department, The estimation of fire outbreak risks in commercial buildings and emergency preparedness for large scale earthquake, 1983

2. Bureau of Fire Defense, Research report on fire caused by Niigata earthquake, 1965

3. Tokyo Fire Department, Report on Miyagiken-oki earthquake of 1978 , 1978

4. Bureau of Science and Technology, Human behavior depending on intensity of quake, 1981 